\title{
Endometriosis Revealed by Recurrent Hemorrhagic Ascites
}

\section{Edouard N'Guessan'1, N'Goran Kouamé2, Jean Marc Lamine Dia1, Franc Gbeli', Privat Guie1, Simplice Anongba ${ }^{1}$}

\author{
${ }^{1}$ Department of Obstetrics and Gynecology, University Hospital of Treichville, Abidjan, Côte d'Ivoire \\ ${ }^{2}$ Department of Radiology, University Hospital of Yopougon, Abidjan, Côte d'Ivoire \\ Email: edouardnguessan@yahoo.fr
}

How to cite this paper: N'Guessan, E., Kouamé, N’G., Dia, J.M.L., Gbeli, F., Guie, P. and Anongba, S. (2017) Endometriosis Revealed by Recurrent Hemorrhagic Ascites. Open Journal of Obstetrics and Gynecology, 7, 1160-1165.

https://doi.org/10.4236/ojog.2017.712117

Received: September 26, 2017

Accepted: November 6, 2017

Published: November 9, 2017

Copyright $\odot 2017$ by authors and Scientific Research Publishing Inc. This work is licensed under the Creative Commons Attribution International License (CC BY 4.0).

http://creativecommons.org/licenses/by/4.0/

\begin{abstract}
Ascites is a rare manifestation of endometriosis. The case reported is that of a 26-year-old woman with recurrent massive hemorrhagic ascites. The analysis of biopsy specimens made at laparoscopy confirmed the diagnosis. The report noted pelvic endometriosis associated but there was no umbilical or pleural involvement. The evolution was favorable under a long-term hormone treatment (by GnRH analogues) with relay through continuous estrogenprogestogen. The diagnostic and therapeutic difficulties of this rare form of endometriosis are presented through a review of the literature.
\end{abstract}

\section{Keywords}

Endometriosis, Hemorrhagic Ascites, Management

\section{Introduction}

Endometriosis is characterized by the presence of endometrial tissue (endometrial gland and stroma) outside the uterine cavity. It is a relatively common benign pathology affecting about $8 \%-10 \%$ of women of childbearing age [1]. Its usual locations are pelvic but with extra-pelvic forms in $1 \%$ of cases [2]. In these extra pelvic forms, the positive diagnosis is made difficult by a heterogeneous clinical symptomatology.

Endometriosis revealed by an ascites is rare and is presented in the form of a recurrent haemorrhagic ascites sometimes associated with pleurisy. The use of laparoscopy with biopsy is often necessary to eliminate any neoplastic or tuberculous pathology. Its treatment is based on long-term hormone therapy with frequent recurrences.

We report the difficulties encountered in the diagnostic procedure and the 
therapeutic attitude in a 26-year-old woman with endometriosis with haemorrhagic ascites.

\section{Observation}

Mrs. KG, 26, of black african origin, nulliparous, was sent by the department of internal medicine to explore an ascites. Its history is unusual (HIV serology negative, negative IDR).

The symptomatology is said to go back to about one year by spread abominal pains with progressive increase of its size. Her initial management in a level 2 health care center in a provincial town where she lived evoked the peritoneal tuberculous diagnosis on indirect arguments: ascites with lymphocytic exudate in a young patient in endemic area.

An antituberculous treatment was imposed for 8 months without success. The evolution was characterized by a significant increase in the abdominal size for which an abdominal ultrasound showeda high ascitic quantity.

She was then addressed to the internal medicine service of our level 3 heath care center, where aperformed MRI revealed an ovarian hypertrophy (54 $\mathrm{mm}$ major axis to the right and $48.8 \mathrm{~mm}$ to the left) associated with ascites (Figure 1). Therefore she was taken to our gynecology service.

In Our service the oriented interrogation found dysmenorrhea evolving since teens and a notion of cyclical abdominal distension of recent onset. The physical examination revealed a stable hemodynamic state, a high quantity of ascites making difficult the pelvic exploration (uterus and annexes), without peritoneal syndrome or occlusive syndrome.

The exploratory puncture brought a haemorrhagic and exudative liquid.

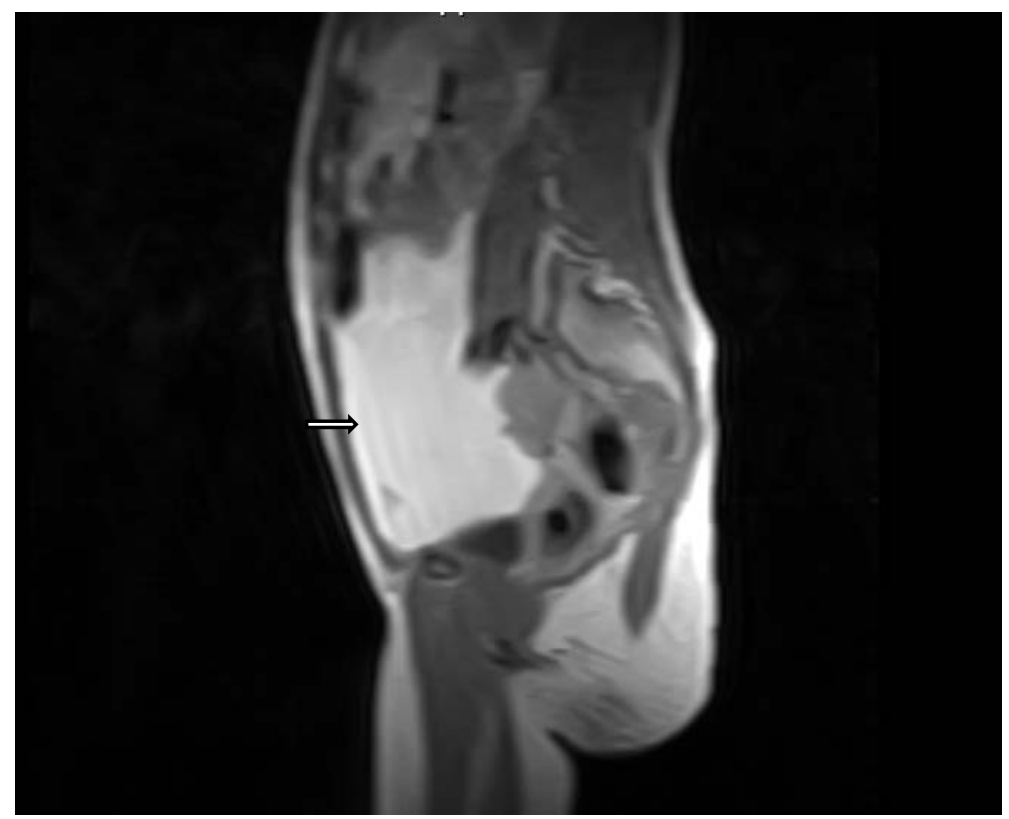

Figure 1. MRI in sagittal section showing high-signal intensity on the T1 sequence suggesting a massive hemorrhagic ascites (arrow). 
Biologically, there was a normal hepatic balance (alanine aminotransferase: 34 IU/l, aspartate aminotransferase: 31 IU/l, gamma-glutamyltransferase: 18 IU/l, alkaline phosphatase: $46 \mathrm{IU} / \mathrm{l}$ and total bilirubin: $2.7 \mathrm{mg} / \mathrm{l})$. The blood analysis also showed, a normal renal evaluation (urea: $0.1 \mathrm{~g} / \mathrm{l}$, creatinine: $4 \mathrm{mg} / \mathrm{l}$ ), a hemoglobin $10.6 \mathrm{~g} / \mathrm{dl}$ and a CA-125 levels raised to $63 \mathrm{IU} / \mathrm{ml}$.

Laparoscopy confirmed the abundance of haemorrhagic ascites (6 liters) with normal liver and gallbladder. The parietal peritoneum was inflammatory bleeding on contact and dotted with brownish spots. The pelvic organs were taken from a magma adhesions that made impossible their exploration. Several biopsies were performed after aspiration of ascites and the histological examination of these pieces was in favor of endometriosis (Figure 2).

An analogue treatment of GnRH was established for six (6) months relayed by a continuous intaking of a monophasic ostroprogestative pill. The evolution was marked by a complete drying up of ascites after three months of treatment and an absence of recurrence after eleven months of decline.

\section{Discussion}

Ascites is a rare manifestation of endometriosis [3]. Since the description of the first case by Brews in 1954 [4], the literature relates only sixty sporadic cases [3]. And in our country there was no case published on that issue.

The characteristics of our patient correspond to the classical profile of the patients usually affected by this rare form of endometriosis. Indeed, the majority of cases reported in the literature concerns young women with an average age of 29 years, of black race (70\% to $80 \%$ of cases) and nulliparous [2] [3] [4].

Ascites associated with endometriosis is generally massive with an average of 3 to 4 liters [2]. The ascites fluid is typically chocolate color, sero-hematic or

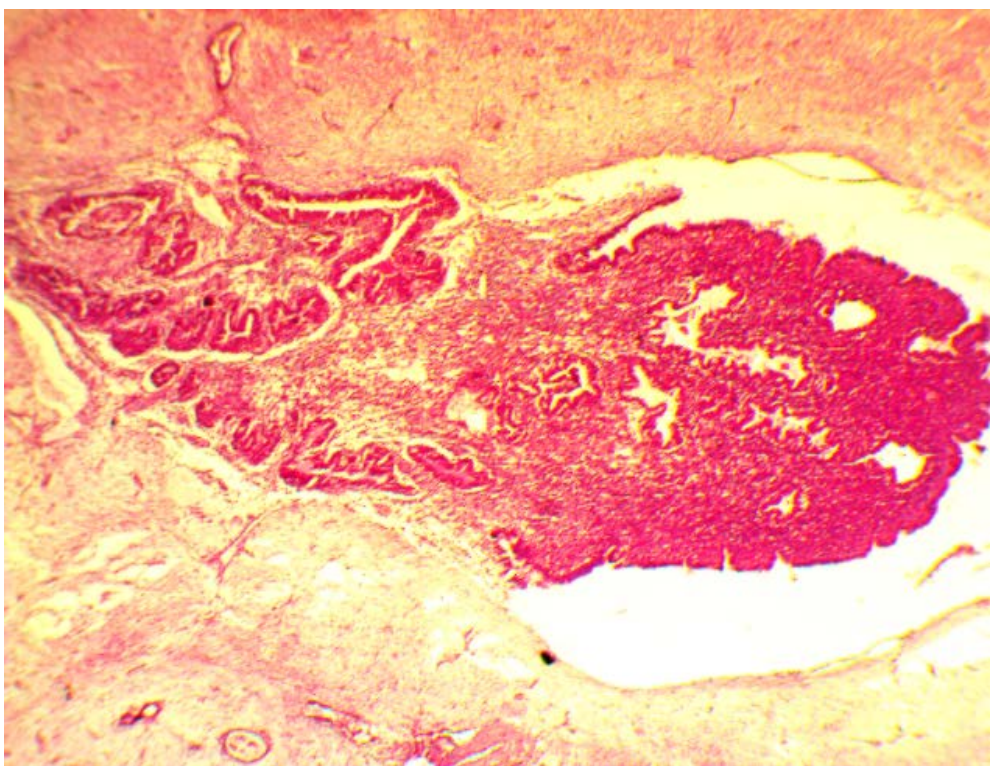

Figure 2. Microscopic examination of the peritoneal biopsy showing endometrial glands and stroma $(\times 50$, HE Stain $)$. 
hemorrhagic as in our case [2] [4] [5].

Ascites can be associated with right hand pleural effusion in about $30 \%$ of cases [3] [5].

The pathogenesis of ascites associated with endometriosis remains unknown. The most mentioned mechanism is the irritation and stimulation of peritoneum by blood and endometriotic cells from a broken endometriotic cyst [5] [6]. Regarding the pleural effusion, it might be due to passage of ascites fluid in the pleura by trans-diaphragmatic or lymphatic way through the thoracic duct explaining its right hand location [4] [5].

The diagnostic difficulties of ascites associated with endometriosis are well known. Indeed facing this type of ascites, practitioners generally evoke, in first intention,peritoneal tuberculosis, neoplastic pathologies, or Demons-Meigs syndrome [3] [7].

Moreover, the presence of an alteration of the general state of a pelvic mass and elevated CA-125 associated with ascitesmake think to ovarian cancer or Demons-Meigs syndrome [4].

Finally, magnetic resonance imaging may reveal lesions suggestive of endometriosis (hyperintense on T1) but does not eliminate the existence of infracentimetric implants [8] [9]. Thus, in most cases, the diagnosis is mentioned only during surgical exploration by laparoscopy or laparotomy and histological examination confirmed by biopsy [4] [10].

However, the authors are unanimous on the diagnostic orientation value of the well-conducted interview [1] [4]. Indeed, the cyclical character punctuated by the menstruation of the symptoms an evocative argument all the more important that it occurs in a patient with a history of dysmenorrhea as in our patient. These dysmenorrheas are found in more than half of women with endometriotic ascites [4].

The analysis of the literature does not reveal a well codified therapeutic strategy to this form of endometriosis.

The hysterectomy with bilateral oophorectomy is the only definitive treatment but its indications are restricted by the young age of the patients and their fertility desire [6]. Complete excision of endometriosis nodes, principle of conservative surgery for endometriosis can not be obtained because of the diffuse nature of the peritoneal involvement and the importance of peritoneal adhesions [7]. Therefore, the authors tend to favor suppressive hormone treatment by GnRH analogs over a period of 6 months but the ascites recurrences in stopping treatment are common [2] [7]. Preventing recurrences of painful symptoms of endometriosis is usually based on a long term prescription of progestative or estroprogestative, but their effect on the development of the ascites is not yet rated [4]. In our observation, the continuous use of estroprogestativein relay of the GnRH analogues saw no recurrence of ascites with eleven months of decline.

The management of infertility in these patients is more difficult and usually requires recourse to in vitro fertilization (IVF) [4]. But be aware that ovarian 
stimulation may induce recurrence of ascites [4] [6].

\section{Conclusion}

The ascites is a rare manifestation of endometriosis which is a severe form of this affection. Its diagnosis is often difficult and requires laparoscopic exploration. However, the cyclical and catamenial symptoms is a strong argument justifying a careful interrogation. The assessment should seek other localizations associated, in particular pelvic, umbilical and right hand pleura. Medical treatment by GnRH analogues gives good answers but relapses are common. The long term use of estroprogestative in relay to GnRH analogues for preventing these recurrences should be evaluated.

\section{Financial Support}

None.

\section{Conflict of Interest}

None.

\section{References}

[1] Giudice, L.C. and Kao, L.C. (2004) Endometriosis. The Lancet, 364, 1789-1799. https://doi.org/10.1016/S0140-6736(04)17403-5

[2] Flanagan, K.L. and Barnes, N.C. (1996) Pleural Fluid Accumulation due to Intra-Abdominal Endometriosis: A Case Report and Review of the Literature. Thorax, 51, 1062-1063. https://doi.org/10.1136/thx.51.10.1062

[3] Gungor, T., Kanat-Pektas, M., Ozat, M. and Karaca, M.Z. (2011) A Systematic Review: Endometriosis Presenting with Scites. Archives of Gynecology and Obstetrics, 283, 513-518. https://doi.org/10.1007/s00404-010-1664-1

[4] Ekoukou, D., Guilherme, R., Desligneres, S. and Rotten, D. (2005) Endometriosis with Massive Hemorrhagic Ascites: A Case Report and Review of the Literature. Journal de Gynécologie Obstétrique et Biologie de la Reproduction, 34, 351-359. https://doi.org/10.1016/S0368-2315(05)82841-8

[5] Samora-Mata, J. and Feste, J.R. (1999) Endometriosis Ascites: A Case Report. JSLS, 3, 229-231.

[6] Fortier, D., Dedecker, F., Gabriele, M., Graesslin, O. and Barau, G. (2005) Endometriosis Presenting with Massive Ascites and Pleural Effusion: A Case Report. Gynecologie, Obstetrique \& Fertilite, 33, 508-510. https://doi.org/10.1016/j.gyobfe.2005.05.014

[7] Shabeerali, T.U., Rajan, R., Kuruvilla, A.P., Noronha, S., Krishnadas, D., Shenoy, K.T., et al. (2012) Hemorrhagic Ascites: Are We Missing Endometriosis? Indian Journal of Gastroenterology, 31, 195-197.

[8] Hartigan, C.M. and Holloway, B.J. (2005) Case Report: MR Imaging in Features of Endometriosis at the Umbilicus. The British Journal of Radiology, 78, 755-757. https://doi.org/10.1259/bjr/68622762

[9] Wampler, K., Harwager, B. and Michael, K. (2017) Abdominal Wall Endometriomas at Cesarean Section Scars: A Case Series. Open Journal of Obstetrics and Gy- 
necology, 7, 815-823. https://doi.org/10.4236/ojog.2017.78082

[10] Suchetha, S., Rema, P., Mathew, A.P. and Sebastian, P. (2010) Endometriosis with Massive Hemorrhagic Ascites. Indian Journal of Cancer, 47, 224-225.

https://doi.org/10.4103/0019-509X.63004 